\title{
How ethnic cultures influence practice-based learning
}

\section{Introduction}

Global mobility of workers has contributed to the very culturally and linguistically diverse workforces in most developed societies (Kazanjian, 2018). Yet, formal training and development approaches to maintain workers' capacities for productivity follow strategies designed for normative populations. That is, ethnic cultural philosophies and approaches to learning of migrants are rarely considered when designing and implementing national curricula for education and training. Hence, workers are left to learn relevant knowledge and skills mainly by engaging in practice-based learning (PBL). For instance, in small-business Chinese restaurants operating in Western countries such as Australia, worker' learning is closely guided and coached by experienced workers (mainly Chinese) who teach the art of Chinese cuisine and hospitality. Such learning in practice settings is essential to offer customers not just Chinese cuisine, but also distinct dining experiences - Chinese style.

The opinions of owners/managers of small business have attracted some research (see, for example, Cairncross, Wilde \& Hutchison, 2008; Shah, 2017). Whitelaw, Barron, Buultjens, Cairncross and Davidson (2009) report that the types of competencies and dispositions that small Chinese restaurant owners seek in their workers are not taught in the formal curriculum offered by educational institutions. Hence, owners/managers prefer in-house training that is, practical and well-integrated with their business operations, albeit with expectations that workers will take the initiative and exercise agency for their learning to remain employed and employable. In these circumstances, a highly contextualised in-course training for workers is intensely influenced by the ethnic culture. This is fine for businesses that are operated by Chinese owners who operate in certain ways that are keen on customers to have a Chinese dining experience. 
However, Richardson and Law (2009) argue that PBL is a central tenet of in-house training in small business settings, cautioning that PBL should not become a substitute for formal learning. Workers may be disadvantaged if their learning is constrained to narrowly defined sets of knowledge and skills or exposure to limited sets of experiences and technologies, thus limiting their employability in other workplaces should they decide to explore opportunities elsewhere. Manuti, Pastore, Seardigno, Giancaspo and Morciato (2015) suggest that decision-makers in small business settings such as Chinese restaurants may not fully appreciate the benefits of formal training programs that offer workers broader competences to work in different sites. They point out that over-contexualised skill sets may reduce learning to simplistic outcomes, instead of transferable skills and knowledge to sustain employability.

A review of recent literature shows a deficit in research on worker-learners' experiences of PBL in small business settings. Moreover, there are no studies on the influence of ethnic cultures on workers' learning in practice settings. The research reported in this paper used a practice theory lens to understand how workers in small-business Chinese restaurants engaged in PBL. The study investigated how workers' learning is enabled or constrained by the practice architecture (Kemmis and Grootenboer, 2008) and Chinese ethnic cultural practices founded on Confucianism.

We commence by outlining the nature and benefits of PBL. Key features of Chinese ethnic culture on learning are then introduced. We go on to explain the theory of practice architecture and the three sets of arrangements (cultural-discursive, material-economic and social-political emergent in the 'sayings', 'doings' and 'relatings') that make up the ecologies of practice in small business Chinese restaurants. The approach to data collection and analysis is then outlined. Following the presentation of the findings, we discuss how the Chinese ethnic cultural practices of wu chang and san gang shape and influence the sayings, doings and relatings to mediate the cultural-discursive, material-economic and social-political arrangements of 
practice architecture in small-business Chinese restaurants. In the concluding sections we list the implications of the findings for practice-based learning and limitations of our study.

\section{Nature and benefits of practice-based learning}

Practice-based learning involves interactions between human, cultural artefacts, and the situational context - mediated by aesthetic knowledge. It was Billett's (2014a) seminal research on understanding how people learn occupations through their work that highlighted the benefits of PBL. There are many advocates of PBL. Yakhlef (2010a) contends that PBL incorporates the facility of embodied learning and presents opportunities for worker-learners to reflect upon what has been experienced and imagined (Yakhlef, 2010b). Shan and Walter (2015) maintain that PBL fosters everyday multiculturalism. This could include different fusion work as well as ethnic cultures. Teunissen (2015) adds that PBL shapes the personal experiences of workerlearners in ways that lead to multiple trajectories with appropriate reifications arising from future activities within the same practice site. Huggins (2017) advocates that PBL is powerful and robust in terms of providing opportunities for worker-learners to apply the knowledge and skills that they have acquired from various sources, including from the work site itself as well as externally. Moreover, when reflective practices are facilitated, learning can be even richer especially through direct guidance by more experienced co-workers (Billet, 1999). There are bilateral benefits of two-way learning and knowledge sharing between novice and experts in the same site of practice (O’Donovan, 2018).

From the above account, the nature of learning in the circumstances of practise is multi-faceted. It comprises the elements of practice curriculum, pedagogies and worker-learners' epistemologies, which are shaped and transformed by cultural, social and situational factors (Billett, 2014a). Learning and change require harmony in the ecology of practice in which workers can learn and at the same time sustain productivity. How ethnic cultures enable or 
constrain such harmony remains less researched. This was of foremost interest to the study reported here.

\section{Ethnic culture in Chinese restaurants}

Workplace cultures are shaped by shared beliefs, assumptions, values and codes of practice that result in unique working environments (Deal and Kennedy, 2000). While the national cultures and normative western business practices dominate workplace cultures, individual workers bring their own cultures and value systems that shape mindsets and influence the deeplevel culture in the workplace (Siah, Ong, Tan \& Sim, 2015). Customary beliefs, social forms, and material traits of racial, religious, or particular social groups form ethnic cultures that add another dimension to workplace cultures, albeit influencing at surface or deep levels (Van Vianen, De Pater, Kristof-Brown \& Johnson, 2004). According to Ashong-Lamptey (2018), ethnic cultures act as a professional resource and influence workers' work-based behaviours and, hence, their approach to service delivery and productivity. The research reported in this paper analysed the influence of Chinese culture, especially the practice of Confucian principles on PBL.

China is a single nation, but by no measure a monoculture. A common feature of Chinese society lies in Confucian doctrines, a heritage that continues to influence people's cultural and behavioural repertoire (Hsu \& Stanworth, 2018). Confucian teachings emphasise hard work, loyalty and social order (Rarick, 2009) expressed as cultural practices of san gang ("three cardinal guides") and wu chang ("the five constant virtues"). San gang professes three principles: (a) the ruler guides subject, (b) father guides son, and (c) husband guides wife. These types of relations underpin work practices, especially in small business settings. For instance, the manager is equated to the 'ruler', more experienced workers guide novices as in a 'father - son' relationship or as in the protective relations between 'husband - wife'. The 
concept of wu chang includes ren ("humanity"), yi ("righteousness"), li ("propriety"), zhi ("wisdom") and xin ("fidelity"). The former practice symbolises the hierarchical structure of Chinese society, and the latter governs the rules for acceptable conduct by society. Rarick (2009) concluded that Chinese cultural values embrace collectivism; harmony; authoritarianism, strong organisational network and business connection; and paternalistic leadership. These Confucian principles illustrated through the five virtues of wu chang that form the foundations of ethical and moral practices are evident in writing of Keller and Kronstedt (2005) and Liu (2017). Confucianism tends to influence how workers conduct themselves in workplaces such as small-business Chinese restaurants and how they engage in PBL. We interpret Chinese culture based on Confucian teachings and how these enhance or constrain PBL in small-business Chinese restaurants. This was investigated through a practice theory lens.

\section{Practice theory}

Practice theory originated from Schatzki's $(2005,2006,2010)$ conceptualisation of "site ontology" as well as the time-space dimensions of human activity, wherein practices are happening on a particular site and in a particular time-space as "temporal-spatial" events. Practice is central to PBL. Hopwood (2014) argues that PBL is performative rather than cognitive, whereas learning is conceptualised as knowing rather than transferring of knowledge. So, learning alone is not sufficient, rather become apparent as performance in practices. Practices comprise sayings, doings and relatings with their own rules and “teleoaffective" structures (Schatzki, 2002). According to Rovio-Johansson (2018), learners' meaning-making and understanding of their learning objects are expressed in their doings and sayings. Schatzki's concept is further extended by Kemmis and Grootenboer (2008) who explain that "sayings", "doings" and "relatings" form key dimensions that mediate three sets 
of arrangements: cultural-discursive, material-economic, and social-political - that collectively comprise the practice architecture of particular sites.

Sayings, doings and relatings together contribute to work outcomes that workers achieve together. Kemmis and Grootenboer (2008) maintain that relatings mediate power and solidary in the social space of a site. In other words, the sayings, doings and relatings are negotiated and reconciled in the corresponding cultural-discursive, material-economic and social-political arrangements of practice architecture. These three sets of arrangements are found in or brought to the sites of practices that shape or reshape the sayings, doings and relatings within the semantic, physical and the social spaces. The cultural-discursive arrangements shape the sayings that provide opportunities for individual participants to communicate appropriately and share their meanings and understandings, in order to orient, justify and harmonise practices. The material-economic arrangements pre-shape the physical set-up within the site of practice that configures the context of the doings. Through the doings, individuals acquire the skills and capacities to function appropriately. The social-political dimension dominates the content and conduct through relatings with other worker-learners. This galvanises the relationship between people to share the values among humans and equipment. These three arrangements are bundled together to shape the practice architecture that constitutes and is constituted in, actions -- sayings, doings and relatings. This bundle is dynamic and is influenced by ethnic and cultural values and practices. Each arrangement interacts with the other, resulting in changes or modifications that lead to the emergence of practice/practices at a site or across other sites, albeit to sustain the ecology of practice.

In this study, we analyse how the sayings, doings and relatings for PBL are enabled or constrained by Chinese ethnic culture.

\section{Methodology}


The study adopted an ethnographic approach to understanding the practice architectures, workplace cultures and social interactions (Denscombe, 2010). Importantly, ethnography gave insights into how members of a culture-sharing group understand their world, the meaning of their actions and behaviours, and how they interpret their realities during PBL. This provided a microcosmic view of learning and work experiences in the 11 case sites located in the southeast of Queensland, Australia. The first author is of Chinese heritage and had worked in small Chinese restaurants. This enabled him to relate to the lives of the participants all of who were of Chinese origin. He captured valuable information from the routines and everyday life of workers in their context. He communicated using common languages (Mandarin or Cantonese) to interpret meanings of their sayings, doings and relatings, and the ways they perceived their reality (Denscombe, 2010). Moreover, he used his cultural knowledge to sensitively build trust with managers and participants throughout this research. As such his own ontological experiences became a currency of advantage for this research.

A convenience sample of 11 SBCRs were approached through personal contact of the first author. Participating restaurants are categorised as small business as per the Australian Bureau of Statistics' definition (i.e., Employing less than 20 workers).

Importantly, managers of these SBCRs willing consented to the study being conducted in their sites. Ethical clearance was obtained from Griffith University. Data were collected from 20 workers. Table 1 shows its details. 
Table 1.

\begin{tabular}{|l|l|l|l|l|l|l|l|l|l|l|l|}
\hline & Site 1 & Site 2 & Site 3 & Site 4 & Site 5 & Site 6 & Site 7 & Site 8 & Site 9 & Site 10 & Site 11 \\
\hline Gender & M, F & M, M & F & M, F & M, F & M, F & M, M & F & M, M & F,M & M, F \\
\hline Age & 55,53 & 55,55 & 42 & 28,35 & 50,50 & 41,41 & 40,38 & 45 & 40,40 & 60,52 & O/C,W \\
\hline $\begin{array}{l}\text { Birth } \\
\text { country }\end{array}$ & V, MY & HK,HK & HK & MC,HK & T, T & MC,HK & HK,HK & MC & HK,HK & HK,HK & V, V \\
\hline Roles & $\begin{array}{l}\text { O/C, } \\
\mathrm{W}\end{array}$ & C, O/C & W & O/RM,W & O/C, C & O/RM,W & RM, W & W & O/MR,O/C & W, C & O/C, W \\
\hline $\begin{array}{l}\text { Years of } \\
\text { experience }\end{array}$ & 40,33 & 40,10 & 21 & 5,15 & 5,5 & 10,30 & 20,15 & 25 & 15,20 & 40,28 & 15,15 \\
\hline
\end{tabular}

M -male; F- female; O-owner; RM-restaurant manager; C-chef; W-wait-staff; V-Vietnam; MY-Malaysia; HKHong Kong; T-Taiwan; MC-Mainland China

As shown in Table 1, all participants were born oversea, and they shared a common cultural heritage based on Confucian teachings. Each participant signed an informed consent. All participants were made aware of their rights of voluntary participation and that they could withdraw at any time without consequences.

Data were collected from face-to-face interviews using semi-structured questions. The questions focussed their experiences in PBL. For instance, the sample was asked to reflect on things they need to learn for their jobs and how they went about learning these through everyday work practices. All interviews were transcribed verbatim by the first author. Each transcription was de-identified, and a pseudo name given to each participant.

Each case study was manually analysed. Researcher listened to the audio files of individual interview records, then verified, coded and categorised transcripts data to identify the sayings, doings and relatings for PBL in each case site. These were then analysed in terms of the three arrangements in the practice architecture. The analysis included in-case exploration and cross- 
case comparison to provide insights into workers' PBL. The findings from the analysis were then verified through site observations to gain an understanding of the context PBL and the practice architecture.

Observations were carried out at different times at the sites so that the researcher could capture cultural practices at each mealtime. Two participating SBCRs were studied in detail. They were selected for the open plan, allowing the unobtrusive researcher observations in both the kitchen and dining areas simultaneously. The physical architecture also facilitated interactions for rich learning by the workers within.

\section{Findings}

As explained earlier, PBL is shaped by cultural, social and situational factors. In restaurants, practices involve the interactions between humans, kitchen equipment and other artefacts in the workspaces that mould and are moulded by behaviours, actions and interpersonal relationships. Additionally, the situational support that exist or are brought to the particular site of practice shape and reshape practices and consequential learning. While some workers in this study had been on the same site since joining the industry, others had worked in different restaurants. They brought with them different ways of working but needed to learn and accommodate particular practices in their current workplaces. Almost all workers acquired their occupational capacities at, in, and from work - through PBL.

Confucian philosophy, like the wu cheng ("five constant virtues") -- ren ("humanity"), yi ("righteousness"), $l i$ (“propriety"), zhi (“wisdom"), xin (“fidelity”) - is implicitly deep-rooted in their mindsets and their being (Xie, Su \& Zhong, 2017). These values govern and inform construction of their identities, approaches to work, and sayings, doings and relatings. In the main, their cultural perspectives enhance or constrain the practice architectures and ecologies of practice at the worksites, and subsequently their learning and productivity. How they learnt 
the sayings, doings and relatings s explained below. The examples presented here are reflective of the experiences of other participants.

\section{Learning the sayings in Chinese restaurants}

In the course of their daily work, workers harmonise restaurant practices through their sayings, doings and relatings. Interactions between workers and the work tools they employ are ubiquitous. A new worker gets immersed in social practices and is expected to learn through observation and mimesis. Mimetic learning involves observation, imitation and action during daily work activities and interactions, both remote from or engaged with others (Billet, 2014b). When Xiao Ying commenced work in her father-in-law's restaurant as a dim sim waitress, her routine tasks included pushing the dim sim trolley around the dining area and introducing and promoting various dim sims for diners to choose from. Xiao Ying was not familiar with dim sims and felt challenged when some Western diners asked her to name the dim sims in the trolley. She had to learn quickly. She observed how the dim sim chef named and explained the ingredients in each to the waitresses. She needed to pay attention to the head chef - following the principle of san gang (ruler guides subject). Xiao Ying wasn't proficient in English but paid particular attention to the intonations of the English names of the dim sims then shouted the names like the other waitresses. Over time, her knowing came from close observation, listening and asking for help from other workers. In this way she learnt the sayings to promote dim sims to customers.

The dim sims chef would tell me about that ... "That is Sou Mai and that is Xia Jiao"... Then I had to ask my aunt how to say them in English in case there were Western diners who asked their names. I needed to recite their names.

(Xiao Ying)

Xiao Ying's success in PBL resulted from min er hao xue practices (i.e. sensitive and eager to learn, always ask questions) and bu chi xia wen (feel not ashamed to learn by asking other 
people who may even be one's subordinates). As well, her agency of yan guan si lu, er tin ba fang (keep the eyes and ears open) during work, her mental practice of san fu si yan (study the words repeatedly to get a thorough understanding), and critical reflection of ju yi fan san (draw inferences about other cases observed during the day) after work, maintained the currency of her sayings and work practices.

I tried to remember how to pronounce the names of the dim sims that I was serving ... I recited the pronunciation continuously myself ... mental practice was my usual method.

They told me that "dumpling" is the skin and "prawn" is "xia", so I treated all the dim sims with similar shape "dumplings". The ingredients determine what kind of dumpling I name.

(Xiao Ying)

Her learning and critical reflection are influenced by Confucian philosophy (xиe er bu size wang; si er bu xue ze dai) -- "learning without thought is labour lost; thought without learning is perilous". She just mimicked what she had been told given there was nobody to guide or mentor her during the peak hours of trading, but verified with experienced workers if needed.

I did it myself because there would not be anyone who followed my work since everybody was busy in the dining area. In addition, other peer workers would not know what kinds of thing that I did not know or I needed to learn.

(Xiao Ying)

Workers also learn in practice settings by observing body language or other non-verbal signals or visual cues (Burgoon, Guerrero \& Floyd, 2016). Xiao Ying's case here is reflective of other workers who learn sayings in practice settings. For instance, Xiao Lin learnt by paying attention to customers' gestures and postures as they studied the wall menu with two choices of main dishes, and complimentary soup and drink.

... those customers who walk in and focus on the wall menu, and you can predict that they will order the set lunch or house specials within one minute ... a waiter needs to focus ... I will wait for a while for them to read the menu and approach them to place their orders. If they do not read the menu and go to get water, these orders must be very easy. I am comfortable that they know what they want. 
(Xiao Lin)

Aside from the body language of customers, other non-verbal communication using sign language is also utilised by the work team. For instance, Xiao Lin joined the tips of his two index fingers facing upward to signal his colleague. His action indicates an order of Set A lunch special. Xiao Lin used the shape of his mouth to say out "boy set" and pointing at the relevant customer table. The other team member decodes his meaning of "Set B" for the customer sitting on the corresponding table. Here the working team needs to have a common understanding of the sign language in their practice setting. These sign languages are created by the workers themselves through social interactions and immersion in the practice sites and these form common ways to communicate and relate to each other.

Similarly, ordering of drinks at the bar would only be written down in short form. For example, one of the waiters wrote down "IOT" to place an order for an iced lemon tea. It is not difficult to infer that the "I" and "T" represent the "iced" and "tea", but the use of "O" and not "L" for lemon is initially puzzling. According to Xiao Lin, "O" is a common standing for lemon because the shape of "O" is the same as numerical "zero", and the Chinese pronunciation is exactly the same as that of "lemon". This example illustrates trans-languaging - use of English and Chinese, which forms a cryptic language understood by workers in Xiao Lin's worksite. Xiao Lin's agency to adapt oneself to changing circumstances (sui ji ying bian) and flexibility in adapting (ling huo bian tong), which are influenced by zhi ("wisdom") -- one of the wu cheng of Confucian philosophy - are critical to sustaining his PBL. He learns the implicit as well as explicit aspects of sayings, appropriated in the semantic space of his restaurant.

\section{Learning the doings in Chinese restaurants}

Schatski (2002) sees PBL as an open-ended, spatially dispersed nexus of sayings and doings. The doings play a significant role in enabling or constraining one's work. For instance, the material-economic arrangements where Wen Xiao worked determined what he had to learn to 
serve appropriately. When Wen Xiao worked as a novice waiter for China Ocean, he needed to learn how to provide "silver service" to diners. This is the basic requirement of fine-dining practice and the trading feature of China Ocean. Service in normal Chinese restaurants involves placing dishes in the middle of the table for diners to help themselves. Unlike other Chinese restaurants in China Ocean, dishes are presented in front of the diners, and wait-staff need to explain how the dishes are prepared, with details of ingredients that are used. Then, empty dishes are collected from the left-hand side -- as a golden rule of silver service.

\section{At China Ocean, silver service included using spoons and forks to distribute portions of meals to individual diners, boning steamed fish, and each waiter being dedicated to look after a certain number of tables (quite American style).}

(Wen Xiao)

Silver service at China Ocean was not new at the time when Wen Xiao joined the work team. The doings are mediated in the physical time-space in the dining area of China Ocean. Unlike in other Chinese restaurants, the "pass" of the kitchen is the virtual border that marks off the chefs' terrain. Wait-staff are only allowed to track orders in front of the "pass" and verbally inform the chef of the next dishes on order. The "pass' which is the physical architecture, enables their work and learning. In China Ocean, a blurred boundary between the kitchen and dining area was established instead, where wait-staff needed to track and prepare the relevant ingredients for their table orders. In other words, their work experiences are not limited to the service just in the dining area. They also need to gain rich knowledge about the ingredients for each dish on the menu. Moreover, they have the opportunity to observe how the chefs prepare the meal. This enriches their knowing of the work tasks in the kitchen. If asked, they needed to explain to the diners about the ingredients and cooking process. The absence of the "pass" at other restaurants demarcated the boundaries and this constrained workers' learning - other than for the narrow set of knowledge and skills they needed for their roles. 
Clearly, working as a novice waiter in such a distinct work culture meant how Wen Xiao participated and coped with the pre-figuration at work supported his PBL. The Confucian thinking of san ren xing, bi you wo shi (when three walk together, there must be one who can teach me) pre-determines access to credible sources, who helped Wen Xiao learn.

... I asked the other peer workers how to use the spoon and fork. The key was questioning ... you always can learn anything if you are willing to ask ... To a certain degree, they would not refuse me. I think that is the Chinese culture: if you are willing to ask, people will at least teach you something. The main point is attitude.

Asked the chef. Asked the Zhi Ma once, then twice to tell me ...

(Wen Xiao)

Wen Xiao's accounts also illustrate a typical example of how the material-economic arrangement of practice architecture enables learning at a site. That is, his workplace affordances offered opportunities to learn about the ingredients, cooking processes and the art of silver service.

Workers also learnt through mimesis and by receiving close guidance from others. For example, Wei Ge learnt the tossing actions of a wok by closely observing and reflecting on the movement of the wrist and the whole arm, in a rhythmic pattern that is unrestrained and natural when performed by an experienced senior chef. He then practised these actions under guidance. Wei Ge had to take initiative and show interest before he was favoured by the senior chef who instructed and guided him.

Pre-arrangements in worksites also place constraints on workers' PBL. When Fan Ge worked for the Red Box as a novice chef, the routines were standardised according to the company's specifications. Recipes of every dish on the menu were pre-set. All the ingredients and sauces were prepared and supplied by the company's central kitchen. The chefs' duties are limited to combining the prepared ingredients and sauces according to the recipes provided and serving 
the orders from the front counter. This arrangement leaves little chance for Fan Ge to learn the processes of making sauces or preparing the required ingredients.

Such an operative strategy for the Red Box is cost-effective. It maintains quality control and reduces demand on human resources. However, these pre-figured doings limit the richness and scope of learning for Fan Ge. In the long run, this also limits his employability across the industry. Similarly, when A-Na worked for the Universal Corner, her doings were constrained by information communication technology. She was required to stand at her allocated station along the preparation bench. Above the bench are the monitors that display the orders entered by staff at the front counter. The process of food preparation takes place along the production line. Individual workers follow the orders to carry out their tasks related only to the part of preparation for which they are responsible. In A-Na's case, she gains fragmented knowledge instead of the complete process of food preparation. The temporal patterns of activity constrained her learning to make improvements or have input for innovation in the food process.

The above three cases of participants' learning experiences illustrate how the culturaldiscursive and material-economic dimension of the practice architecture enables and constrains PBL. The practice architecture in Wen Xiao's restaurant is more conducive to PBL though gave them sufficient opportunities to learn for their narrowly defined roles. The arrangements at Fan Ge and A-Na's restaurants constrained their development through PBL. If Fan Ge and A-Na maintained the doings at their restaurants following mo shou cheng gui, yi cheng bu bian (stick to the rules without changes), their PBL would continue to remain limited. They will not be able to expand their occupational capacities. However, their realisation of fragmented learning led them to activate Confucian teaching on zhi (wisdom) of wu cheng and san xing wu shen (self-reflection). Fen Ge and A-Na sought help from other experienced workers to enrich their knowing by building good relationships (relatings) with peer workers. 


\section{Learning the Relatings in Chinese restaurants}

Confucian teachings are humanistic, obligation based, and collectivistic in nature (Ip, 2009). These features form the foundation for social relationships and maintenance of harmony as being of utmost importance for Chinese society. The concept of guanxi (relationship) is also key to enhancing harmony within workplaces, such as Chinese restaurants. Participants in the study engaged in relatings that are mediated in the social space supported by the social-political arrangements of practice settings. This is illustrated in the case stories of A-Da, Wei Ge, Fan Ge and Xiao Lin.

Across the cases, participants attributed their success from learning at work to efforts placed on initial building and continuous maintenance of good guanxi with their seniors at work. A$\mathrm{Da}$, who was a novice worker, devoted himself to working hard. He impressed his seniors by being self-motivated and helping other workers during his routine duties, break times, and even on his day off.

I would make use of my day off and went back to help and learn how to do things in that position. It was a volunteer job to stand next to Shou long and gave him a hand for minor duties.

$(A-D a)$

In this way, he secured very strong social networks in the restaurant. His diligence, attitude and strict obedience to the seniors was quickly recognised and rewarded. He gained high esteem in the community of practice. The head chef urged the other seniors to provide more opportunities for him to practise in the kitchen.

I was lucky that the head chef introduced me to all the chefs on the first day of me working in that kitchen, which made the other chefs look after me. It was so important that the head chef asked the other senior chefs to look after me.

$(A-D a)$ 
A-Da had to "earn" advantages and opportunities. Such incidences of securing personal opportunities for learning through practice by building good guanxi are not exclusive to A-Da. Other participants such as Wei Ge, Xiao Lin and Fan Ge also reported similar efforts in building good guanxi with their seniors -- as enablers that create learning opportunities and subsequent progress in capacity building.

He was an old man and I was a young boy who always accompanied him for a morning walk in the garden ... I got on very well with him, he invited me to join him working for a new restaurant ... teach me the "tricks of the trade" ...

(Wei Ge)

Made a rapport with the manager ... I kept chatting with him after work at 10 pm till midnight ... I listened to his story; sometimes, he would teach me some "tricks of the trade" in how to be a waiter. Moreover, he would mention to me how to do customer service as well.

(Xiao Lin)

My strategy is to work hard to bring a good impression to the Hong Kong chef so he would not mind to teach me. At the end, he was very happy with my achievement.

(Fan Ge)

Each of these accounts suggests that learners need to navigate in culturally appropriate ways to earn a right to learn. Essentially, the concerted efforts in building guanxi with their seniors is instrumental. Their contributions to relatings in the worksite, as illustrated by helping other peer workers and looking after an elderly senior, can be directly sourced to Confucian teachings. Such motivation is underpinned by elements of wu chang (the five constant virtues): ren (willing to look after the elderly); $y i$ (devoting to help other peer workers); $l i$ (following the rule of hierarchy in the kitchen); zhi (diligent attitude to work hard for good performance); and $x$ in (high obedience to senior).

The teaching of the "tricks of the trade" by the seniors is reflected in the Confucius belief of lao wu lao, yi ji ren zhi lao; you wu you, yi ji ren zhi you (respect the elders of own family and the others; looking after the young of own family and the others). Examples of this belief are 
illustrated by the head chef in A-Da's accounts, the old superior in Wei Ge's case, and the Hong Kong chef working together with Fan Ge, who devoted themselves to looking after their subordinates. While guidance, mentoring and coaching are somewhat expected in all workplaces, there is a distinct difference here in that these practices arise gradually through building guanxi, trust and by demonstrating loyalty. This is the nature of relatings in the Chinese context. There is also a caveat here -- subordinates must earn the appreciation of their seniors through respectful attitudes. This exemplifies another Confucian principle -- zun shi zhong dao (honour the teacher and respect his teaching).

A-Da's case suggests that not only wu chang ("the five constant virtues") but also san gang ("three cardinal guides") were embedded in his situation. His obedience to other senior chefs and the head chef earned him the affordances for PBL. Generally, Chinese workplaces follow cultural values similar to those held in their families. The head chef in the dim sim kitchen is the ruler; his command governs other workers. Obedience also embraces the xin, one of the elements of wu chang, which relates to fidelity, as well as $y i$, the sense of righteousness. Both motivated the seniors to help other workers, who are considered as part of a "family".

To this end, the informants' learning trajectories demonstrate how the relatings, mediated in the social space of the workplaces, are enhanced by the social-political arrangements of practice architecture. The ethnic culture pre-determines how worker-learners conduct their social interactions and construct their moral behaviour, particularly in terms of building strong social networks with their seniors or peer workers.

\section{Discussion}

The findings show that individual and collective practice in workplaces constitutes, and is constituted by, the sayings, doings and relatings, which harmonise arrangements in the practice architecture of the worksite. The sayings, doings and relatings and the practice architecture in 
a site enable and constrain PBL. These three elements also complement and moderate functions such as qu chang by duan (overcome one's weakness by acquiring other's strong points) - a Confucian philosophy. For examples, the limitations when learning the doings in Fan Ge's PBL is complemented by the strong relatings between Fan Ge and the Hong Kong chef. Xiao Ying's PBL and the virtue of her perseverance is complemented by relatings to help run her father-in-law's business. These examples suggest that work and learning extend beyond just a "job" and embrace the collective social practices that support PBL. This finding supports those of Richardson and Law (2009).

The findings illustrate how Chinese ethnic culture underpin individuals' mindsets and leads them to engage and participate in their communities of practice. Confucianism dominates their moral conduct that pre-determines how they conduct themselves as worker-learners. The empirical findings of this study echo what Hsu (2002), quoted by Ryu, Zheng and Han (2019) described Asian workers (eg., Taiwanese) working in Australia who are highly influenced by Confucianism. Ryu et al. (2019) assert that people from the countries or regions of Confucian cluster, such as China, Taiwan, Hong Kong, South Korea, Japan, Vietnam, and Singapore are highly influenced by the values inherited from Confucianism. Similarly, for the participants in this study, their ethnic culture governs their perceptions and practices during social interactions.

Yao, Arrowsmith and Thorn (2016) assert that Confucian principles, as a cultural framework, inform employees' motivation, decision-making and their interpretations of experiences. Confucianism plays an important role in influencing employees perceived needs, goods and priorities. Conduct of participants is governed by their values and beliefs underpinned by Chinese ethnic culture. Because human, material, aesthetic, emotive and ethnic elements are embedded in the process of PBL (Hopwood, 2014), workers' cultural heritage needs to be capitalized for PBL at work. In worksites that were included in the research, the cultural- 
discursive arrangements shaped the sayings and provided opportunities for individual participants to communicate and learn through practice. The material-economic arrangements facilitated the context for relevant doings. The social-political dimensions enabled relationships between people to share the values among humans and equipment. These three arrangements bundled together to shape the practice architecture. The ethnic and cultural values and practices influenced the arrangements and to sustain the ecology of practice, PBL and the business functions.

\section{Implications for practice-based learning}

This study analysed the significance of ethnic cultures on PBL in particular sites. The values and beliefs of workers form useful tools to create a harmonious ecology of practice. Workers' cultural beliefs and practices influence their learning of the sayings, doings and relatings and, subsequently, the shaping and re-shaping of practice architecture at work sites. The sayings, doings and relatings also allow workers to exercise their agency to actively engage or not engage in PBL. The understandings gained from the findings of this study form a useful basis for curriculum development and instructional design of training programs for practice-based as well as work-integrated-learning components of vocational curriculum.

Furthermore, this paper informs ways of ethnic cultural practices can form an integral feature of practice architecture, and as part of good practice-based pedagogy. As advised by AshongLamptey (2018), these form a useful professional resource that can be used to influence workers' learning in practice settings. Owner/managers could be made aware of the strengths of the ethnic culture to afford more supportive learning environments for workers.

\section{Limitations}

The study reported here is based on 11 case study sites and a small number of participants (20) albeit gives an insight into how Asian workers' learning approaches are influenced by 
Confucianism. The understandings presented here need to be verified through more research in different regions and nations. In addition, cross-cultural studies on other ethnic restaurants may contribute to deeper understandings of the influences of ethnic culture on practice-based learning.

\section{References}

Ashong-Lamptey, J. (2018), “An exploration of minority ethnic culture as a professional resource", Journal of Business Diversity, 18 (2), 113-132.

Billett, S. (1999), “Guided learning at work”, in Boud, D. and Garrik, J. (Eds.), Understanding Learning at Work, Routledge, London, pp. 151-164..

Billett, S. (2014a), "Learning in the circumstances of practice", International Journal of Lifelong Education, 33 (5), 674-693, http://dx.doi.org/10.1080/02601370.2014.908425

Billett, S. (2014b), "Mimesis: learning through everyday activities and interactions at work", Human Resource Development Review, 13 (4), 462-482.

Burgoon, J.K., Guerrero, L.K. and Floyd, K. (2016), Nonverbal Communication, Routledge, New York, USA.

Cairncross, G., Wilde, S.J. and Hutchison, L. (2008), "Training and service quality - a case study analysis of regional Australian restaurants", Tourism and Hospitality Planning \& Development, 5 (2), 149-163.

Deal, T.E. and Kennedy, A.A. (2000), Corporate Culture: The Rites and Rituals of Corporate Life, Da Capo Press, London.

Denscombe, M. (2010), The Good Research Guide: For Small-Scale Social Research Projects, 
4th ed., Open University Press.

Hopwood, N. (2014), "Four essential dimensions of workplace learning", Journal of Workplace Learning, 26 (6/7), 349-363, doi:10.1108/JWL-09-2013-0069

Hsu, P. S. (2002) Managing across cultures: Motivating Taiwanese employees in the Australian context (Unpublished Honour's degree thesis). University of Queensland, Brisbane, Australia.

Hsu, R.S. and Stanworth, J.O. (2018), "Work as good - mined undertakings and effortless assignments: Chinese meaning of working for hospitality workers and its motivational implications", Journal of Organizational Behaviour, 39, 52-66, doi:10.1002/job.2209

Huggins, S. (2017), "Practice-based learning in higher education”, Library Trends, 66 (1), 112.

Ip, P.K. (2009), “Is Confucianism good for business ethics in China?”, Journal of Business Ethnics, 88, 463-476, doi:10.1007A10551-009-0120-2.

Kazanjian, C.J. (2018), “Toward developing a descriptive multicultural phenomenology", Pedagogy, Culture \& Society, available at: https://doi.org/10.1080/14681366.2018.1469544 (accessed 01 May 2019).

Keller, G. F. \& Kronstedt, C. R. (2005) Connecting Confucianism, communism, and the Chinese culture of commerce. The Journal of Language for International Business, 16, 60-75. Retrieved from http://search .proquest/com/docview/197242194?accountid$\underline{11441}$

Kemmis, S. and Grootenboer, P. (2008), "Situating praxis in practice: practice architectures 
and the cultural, social and material conditions for practice", in Kemmis, S. and Smith, T. J. (Eds.), Enabling Praxis: Challenges for Education, Sense Publishers, Rotterdam, The Netherlands, pp. 37-64.

Liu, P. (2017) A framework for understanding Chinese leadership: a cultural approach. International Journal of Leadership in Education, 20(6), 749-761, DOI:10.1080/13603124.2016.1245445

Manuti, A., Pastore, S., Scardigno, A.F., Giancaspo, M.L. and Morciano, D. (2015), "Formal and informal learning in the workplace: a research review", International Journal of Training and Development, 19 (1), 1-17.

O’Donovan, D. (2018), “Bilateral benefits: student experiences of work-based learning during work placement", Industry and Higher Education, 32(2), 119-128, doi:10.1177/0950422218761273

Rarick, C.A. (2009), "The historical roots of Chinese cultural values and managerial practices", Journal of International Business Research, 8 (2), 59-66.

Richardson, S. and Law, V. (2009), “Changing forms of employment and their implications for the development of skills", Australian Bulletin of Labour, 35 (2), 355-392.

Rovio-Johansson, A. (2018), "Experiences of practice-based learning in phenomenographic perspective", Journal of Workplace Learning, 30 (1), 48-64, available at: https://doi.org/10.1108/ JWL-03-2016-0017

Ryu, K., Zheng, Z. \& Hans, S. (2019) Confucianism and Generation Y: how do two contrary value sets influence the hotel industry and East Asian young employees. Journal of Tourism and Cultural Change, 14(4), 394-415, DOI:10.1080/14766825.2019.1591685 
Schatzki, T.R. (2002), The Site of the Social: A Philosophical Account of the Constitution of Social Life and Change, University of Pennsylvania Press, University Park, TX.

Schatzki, T.R. (2005), "Peripheral vision - the sites of organization”, Organization Studies, 26 (3), 465-484.

Schatzki, T.R. (2006), “The time of activity”, Continental Philosophy Review, 39 (2), 155-182.

Schatzki, T.R. (2010), The Timespace of Human Activity: On Performance, Society, and History as Indeterminate Teleological Events, Lexington, Lanham, MD.

Shah, C. (2017), Employers' Perspectives on Training: Three Industries, NCVER, Adelaide.

Shan, H. and Walter, P. (2015), “Growing everyday multiculturalism: practice-based learning of Chinese immigrants through community gardens in Canada", Adult Education Quarterly, 65 (1), 19-34, doi:10.1177/0741713614549231

Siah, P.C., Ong, B.C., Tan, S.M. and Sim, C.P. (2015), "Perception on Chinese values: a comparison of Chinese secondary students studying at national secondary schools and Chinese independent schools in Malaysia”, The Social Science Journal, Vol. 52 No. 1, pp. 62-28, available at: https://doi.org/10.1016/j.soscij.2014.08.006

Teunissen, P.W. (2015), "Experience, trajectories, and reifications: an emerging framework of practice-based learning in healthcare workplace", Advances in Health Sciences Education, 20 (4), 843-856, doi:10.1007/s10459-014-9556-y

Van Vianen, A.E.M., De Pater, I.E., Kristof-Brown, A.L. and Johnson, E.C. (2004), "Fitting in: surface- and deep-level cultural differences and expatriates' adjustment", Academy of Management, 47 (5), 697-709. 
Whitelaw, P., Barron, P., Buultjens, J., Cairncross, G. and Davidson, M. (2009), “Training needs of the hospitality industry", Sustainable Tourism Cooperative Research.

Xie, T., Su, D. and Zhong, N. (2017), "Confucianism as canonic culture”, Asian Journal of Social Psychology, 20, 170-175.

Yakhlef, A. (2010a), “The corporeality of practice-based learning”, Organization Studies, 31 (4), 409-430, doi:10.1177/0170840609357384

Yakhlef, A. (2010b), "The three facets of knowledge: a critique of the practice-based learning theory", Research Policy, 39 (1), 39-46.

Yao, C., Arrowsmith, J. \& Thorn, K. (2016) Exploring motivation in Chinese corporate expatriation through the lens of Confucianism. Asia Pacific Journal of Human Resources, 54(3), 312-331, doi:10.1111/1744-7941.12097 